М. В. Друзин

Отечественные архивы

и пользователи: проблемы взаимоотношений в начале XXI века

DOI: $10.31518 / 2618-9100-2018-2-13$

УДК 930.25

Выходные данные для цитирования:

Друзин М.В. Отечественные архивы и пользователи: проблемы взаимоотношений в начале XXI века // Исторический курьер. 2018. № 2. Статья 13. URL:

http://istkurier.ru/data/2018/ISTKURIER-2018-2-13.pdf
Druzin Mikhail V*

\section{Russian Archives and Their Users: Communication Problems at the Beginning of the 21st Century}

DOI: $10.31518 / 2618-9100-2018-2-13$

How to cite:

Druzin Mikhail V. Russian archives and their users: communication problems at the beginning of the 21 st century // Historical courier, 2018, \# 2. Article 13. [Available online:]

http://istkurier.ru/data/2018/ISTKURIER-2018-2-13.pdf

Abstract: The article analyzes retrospectively the practice of interaction and relationships between Russian archives and researchers over the past two decades. The author highlights the problems of communication of archivists and researchers due to the lack of jobs in the reading rooms of archives, inflated prices for services that archives provide to users, and the general lack of working tools and methods of mutual communication. A considerable part of current problems, at least those in the regional archives, is explained as a consequence of growing people's interest to private genealogical search. Demand for archival documents of the genealogical character has been growing steadily over the last 10-12 years. This results in the problem of the reading rooms' overload (not enough working places) as well as the stuff overload (asked for consultations by people deprived of basic professional knowledge of historian). The issue of copying archival documents turned to be one more stumbling-block in relations between the Russian archives and the researchers. The author tells the story of the researchers' struggle for the right of free photocopy, of discussions at conferences and social networking sites on this issue. The existing forms of interaction are characterized: official appeals of citizens, public councils, social networks, volunteer organizations.

Keywords: Russian archives; reading rooms; users; communication problems; document copying; social networks.

The article has been received by the editor on 11.11.2018.

Full text of the article in Russian and references in English are available below.

Аннотация: Ретроспективно анализируется практика взаимодействия и взаимоотношений российских архивов и исследователей на протяжении последних двух десятилетий. Обозначены проблемы коммуникации архивистов и исследователей, обусловленные нехваткой рабочих мест в читальных залах архивов, завышенными ценами на услуги, которые архивы оказывают пользователям, и в целом отсутствием рабочих инструментов и методов взаимного общения. Значительную часть современных проблем, по крайней мере - в региональных архивах, автор связывает с ростом интереса простых людей к родословным исследованиям. Востребованность архивных документов генеалогического характера за последние 10-12 лет неуклонно возрастает. Это порождает проблему перегруженности читальных залов, в которых не хватает мест, и проблему перегруженности

\footnotetext{
* Друзин Михаил Викторович, канд. ист. наук, независимый исследователь, г. Санкт-Петербург (Россия), e-mail: mdruzin@mail.ru

Druzin Mikhail Viktorovich, candidate of sciences (history), independent researcher, St. Petersburg (Russia), e-mail: mdruzin@mail.ru.
} 
сотрудников, которые вынуждены давать элементарные разъяснения пользователям, не являющихся профессиональными историками. Еще одним серьезным камнем преткновения во взаимоотношениях архивов и пользователей стал вопрос копирования архивных документов. Изложена история судебной борьбы пользователей в 2016-2018 гг. за право бесплатного фотографирования документов, обсуждения этого вопроса на конференциях и в социальных сетях. Охарактеризованы существующие формы взаимодействия: официальные обращения граждан, Общественные советы, социальные сети, волонтерские организации. Предложены доводы в пользу открытия архивных документов для пользователей.

Ключевые слова: российские архивы; читальные залы; пользователи; проблемы коммуникации; копирование документов; социальные сети.

Для широкой общественности проблема взаимоотношений архивов и пользователей периода современности не стоит вовсе, т. к. абсолютное большинство граждан весьма в общих чертах представляет себе, что такое архив, какие функции в рамках государства он выполняет, и какие информационные возможности скрыты в его хранилищах.

Чтобы представить себе круг лиц, активно вовлеченных в этот процесс, приведем такие официальные данные: в 2017 г. читальные залы федеральных архивов (а это - 15 архивов, расположенных в Москве и Московской области (11), Санкт-Петербурге (2), Самаре (1) и Владивостоке (1)) лично посетили 15636 пользователей ${ }^{1} 7$ государственных архивов СанктПетербурга приняли за тот же год 3636 исследователей $^{2}$, а, например, в читальном зале крупного регионального архива — Центрального архива Нижегородской области зарегистрировано 825 пользователей ${ }^{3}$.

Точное количество уникальных пользователей посчитать сложно: в прошлом году меня как пользователя читального зала учли четыре раза, т.к. пришлось поработать в двух федеральных (РГИА, РГАВМФ) и в двух государственных (ЦГА СПб, ЦГИА СПб) архивах. По самым грубым оценкам число уникальных пользователей читальных залов федеральных и государственных архивов не превышает 50 тыс. человек. А в это количество включены также иностранные граждане, пусть их доля и малочисленна. На фоне 140-миллионного совершеннолетнего населения России 50 тыс. пользователей архивов срываются в статистическую погрешность.

Для сравнения укажем, что в 2007 г. (для более раннего периода нам не удалось найти открытых данных) количество пользователей читальных залов федеральных архивов исчислялось в 9 тыс. человек. При этом в докладе руководителя Росархива сделана оговорка, что «из-за крупномасштабного перемещения фондов в новые здания и необеспеченности ${ }^{4}$ кадрами были закрыты читальные залы РГАВМФ и РГИА», а «во второй половине года закрылся на капитальный ремонт читальный зал ГАРФ и РГАЭ» 5 .

\footnotetext{
${ }^{1}$ Артизов А. Н. Об итогах работы Федерального архивного агентства в 2017 году, задачах на 2018 год и среднесрочную перспективу: Доклад руководителя Федерального архивного агентства на расширенном заседании коллегии Росархива (Москва, 20 марта 2018 г.). Слайд 18. URL: http://archives.ru/reporting/reportartizov-2018-kollegia.shtml (дата обращения: 10.11.2018).

2 Отчет о выполнении основных направлений работы государственных казенных учреждений, подведомственных Архивному комитету Санкт-Петербурга в сфере архивного дела за 2017 г. / Архивный комитет Санкт-Петербурга. СПб., 2018. С. 53.

${ }^{3}$ Подведены итоги работы Центрального архива Нижегородской области за 2017 год. 23 января 2018 // Сайт Государственной архивной службы Нижегородской области. URL: http://www.archiv.nnov.ru/?id=9758 (дата обращения: 10.11.2018).

${ }^{4}$ В источнике - «необеспеченностью»: явная опечатка.

${ }^{5}$ Козлов В. П. Об итогах работы Федерального архивного агентства и его учреждений в 2007 г. и задачах на 2008 г.: Доклад руководителя Федерального архивного агентства на заседании расширенной коллегии Федерального архивного агентства (20 февраля 2008 г., Москва). URL: http://portal.rusarchives.ru/ news/kozlov2008.shtml (дата обращения: 10.11.2018).
} 
Однако даже такое количество пользователей вызвало у российских архивов, особенно региональных, существенные затруднения. Инфраструктура советской архивной системы была рассчитана на разрешительный порядок допуска исследователей-специалистов в читальные залы, что определяло вместимость последних и штат сотрудников, а «Основы законодательства Российской Федерации об Архивном фонде Российской Федерации и архивах» 1993 г. в первом абзаце статьи 20 провозгласили всеобщий доступ к Архивному фонду Российской Федерации ${ }^{1}$. Вместе с тем, практических мероприятий в федеральных и региональных архивах, предупреждающих широкий наплыв посетителей и повышенную востребованность архивных документов, за редкими исключениями, проведено не было. Собственно, первые 10-15 лет периода открытости архивов прошли относительно спокойно в этом отношении. Обычные граждане России не сразу поняли, что такое исторический архив, чем он может быть интересен и полезен для них. Но осознано ли было федеральной архивной администрацией то обстоятельство, что широкой публикой могут быть активно востребованы архивные документы генеалогического и краеведческого характера?

19 октября 2009 г. в эфире Первого канала вышел первый выпуск телепередачи «Моя родословная» с участием актрисы Елизаветы Боярской в качестве героини выпуска. В описании проекта говорилось: «История большой страны складывается из истории каждой семьи. В судьбе любой семьи, как в капле, отражается судьба целой страны... XX век был трагическим для России. Горели архивы, уничтожались документы, скрывались факты. Войны, революции, террор и репрессии почти лишили нас прошлого. Но никогда не поздно связать разорванные нити!»².

Проект являлся аналогом британского - «Родословная семьи» («Who Do You Think You Are?», 2004), и успешно был принят российской аудиторией. Нет уверенности, что авторы русифицированной версии подумали о возможных последствиях популярности передачи для российских архивов. А аудитория Первого канала - граждане России и стран СНГ.

Главная мысль, которую несла в себе программа, - «поиск своей родословной - это не так сложно» - в российских условиях оказалась ложной.

Сложно сказать, стала эта телепередача причиной или следствием повышенного интереса к истории семьи со стороны обычных граждан, но только востребованность архивных документов генеалогического характера за последние 10-12 лет неуклонно возрастает, став сегодня для ряда региональных архивов серьезной проблемой.

Помимо переполненности небольших читальных залов архивов, когда от пользователей требовалось даже предварительно записываться для работы с документами (данная проблема по-прежнему остается актуальной), архивисты столкнулись с тем, что к ним стали обращаться за помощью не подготовленные историки или исследователи из ряда смежных научных специальностей, а обычные граждане, не владеющие элементарными знаниями. При этом доля подготовленных пользователей стала сокращаться ввиду последовавших «оптимизаций» высшего образования и научно-исследовательских институтов, общего сокращения государственных расходов на науку и образование. Сегодня соотношение профессиональных исследователей, работающих по научным темам либо по заданию научно-исследовательского, музейного и т.п. учреждений, и исследователей, занимающихся историей собственной семьи и края, в федеральных архивах можно оценить как 50/50, в региональных архивах это соотношение меняется в пользу исследователей«неспециалистов».

Проблема перегруженности читальных залов решалась и решается в зависимости от финансовых возможностей архива: либо строятся новые здания архивов, в которых

\footnotetext{
1 Основы законодательства Российской Федерации об Архивном фонде Российской Федерации и архивах. 7 июля 1993 года. № 5341-1. URL: http://archives.ru/documents/fz/zakon-fz-1993.shtml?fbclid= IwAR1LhTmPJ9tgc47nYZN9cUrvhfxHm8MFDu-RUKEocnYa_MwcmkNZVGOAxJM\#5 (дата обращения: 10.11.2018).

${ }^{2}$ Моя родословная. О проекте // Сайт Первого канала. URL: https://www.1tv.ru/shows/moya-rodoslovnaya (дата обращения: 10.11.2018).
} 
читальные залы изначально рассчитываются на большее количество мест, либо архив пытается оцифровать наиболее востребованные документы (преимущественно генеалогического характера) и сделать их доступными (платно или бесплатно) через сеть Интернет. Здесь можно назвать ряд архивов, добившихся значительных успехов на последнем направлении: государственные архивы Санкт-Петербурга - ЦГА СПб, ЦГИА СПб, ЦГАИПД СПб, Государственный архив Пермского края, Государственный архив Ярославской области; в том же ряду Астрахань, Воронеж, Красноярск, Самара, Тула, Тюмень, Челябинск, Югра и некоторые другие города. Но во многих региональных архивах, да и в некоторых федеральных, до сих пор не доступен через сеть Интернет даже научносправочный аппарат, хотя бы в виде отсканированных описей.

Проблема неподготовленности пользователей также решается по-разному. Здесь надо отметить, что сами пользователи прекрасно самоорганизуются в социальных сетях, на генеалогических форумах и помогают друг другу практическими советами по работе в конкретных архивах, обмениваются добытой информацией из разных архивохранилищ страны. Архивы, со своей стороны, пытаются наладить процесс коммуникации с новой для них публикой, проводя ознакомительные и обучающие семинары по работе с архивными документами, производству архивного поиска. Однако данная тенденция в отношении к пользователю не стала пока доминирующей.

Еще одним серьезным камнем преткновения во взаимоотношениях архивов и пользователей стал вопрос копирования архивных документов. До 2016 г. архивное ведомство являлось монополистом в предоставлении услуги по изготовлению копий архивных документов. До определенного момента времени, а именно - до широкого распространения различных электронных гаджетов, позволяющих делать снимок и тут же видеть его результат, - это выглядело вполне естественно и вопросов у пользователей не вызывало. В самом деле, не понесешь же с собой в архив ксерокопировальный аппарат или сканер. Впрочем, фотоаппараты известны давно. Но тут играли свою роль несколько факторов: во-первых, архивы, как находившиеся в советское время в структуре НКВД-МВД, продолжали нести на себе ореол некоего ограничения возможностей и прав пользователя по доступу и использованию архивных документов. К тому же, даже в государственных публичных библиотеках запрет на фотокопирование книг собственными техническими средствами был снят всего лишь 3-4 года назад. Во-вторых, исследователи всех «категорий» откровенно побаивались и побаиваются, за единичными исключениями, вступать в открытый конфликт с архивом, опасаясь закрытия доступа в читальный зал или ограничений в выдаче нужных архивных документов. Эти факторы позволяли архивам чувствовать себя в вопросе копирования архивных документов свободно и вольготно, что неадекватным образом отразилось на ценообразовании стоимости копии (сначала - ксерокопии, а позже цифровой копии) документа. Но помимо высоких цен на копирование (от 100 до 1000 руб. за копию одной стороны листа архивного дела в зависимости от качества копии, формата документа и сроков исполнения), пользователей возмущали сроки изготовления копий, способы их предоставления пользователю и в целом вся бюрократическая процедура оформления договора, долгая и неудобная.

В конечном итоге, не выдержало терпение у одного пользователя - кандидата биологических наук, занявшегося собственной родословной, Андрея Галиничева из Нижнего Новгорода. Имея к тому времени опыт судебного оспаривания отдельных норм архивного законодательства (в 2014 г. он успешно оспорил ограничение Федерального архивного агентства на выдачу дел в читальный зал совокупным объемом не более 1500 листов), Андрей Галиничев в январе 2016 г. обратился с иском в Верховный Суд Российской Федерации, в котором оспорил запрет на копирование архивных документов собственными техническими средствами. 28 марта 2016 г. Верховный Суд иск удовлетворил, а последующие апелляции Федерального архивного агентства были отклонены. Научное историческое сообщество с энтузиазмом восприняло эту победу рядового пользователя, однако поддержка по большей части носила только моральный характер. Журнал 
«Историческая экспертиза» взял интервью у Андрея Галиничева и помогавшего ему юриста Дмитрия Пославского, в котором можно подробно ознакомиться со всеми перипетиями этого исторического процесса ${ }^{1}$.

Это решение Верховного Суда Российской Федерации стало рубежной чертой во взаимоотношениях архивной отрасли в лице Федерального архивного агентства и пользователей архивной информацией в лице двух десятков активистов при молчаливой поддержке, к слову сказать, не только пользователей, но и некоторых архивистов, осознавших произошедшую смену эпох. На заседаниях научно-методических советов архивных учреждений по федеральным округам представители Росархива прямо говорили, что своих позиций они сдавать не намерены и будут бороться до конца.

Дальнейшие обсуждения этого вопроса на различных площадках, как виртуальных, так и реальных, оперировали терминами военного противостояния. Еще раз подчеркнем, что позиция по вопросу самостоятельного копирования архивных документов, а на сегодняшний день - по вопросу платности/бесплатности такого копирования - архивного сообщества далеко не едина. Однако Федеральное архивное агентство, переподчиненное в апреле 2016 г. непосредственно президенту Российской Федерации, давит своим авторитетом, не предоставляя возможности свободной дискуссии ни в среде архивистов, ни в диалоге архивистов с пользователями. Но такие обсуждения все же возникают по инициативе наиболее активных пользователей, в частности, в социальных сетях.

Так, 14 ноября 2017 г. Кириллом Белоусовым на его странице в социальной сети Facebook было инициировано обсуждение статьи доктора исторических наук Юлии Юрьевны Юмашевой «Международный опыт решения проблемы самостоятельного цифрового копирования в читальных залах архивов и библиотек» (Историческая информатика. 2017. № 2. С. 95-133). Сама статья стала следствием решения Верховного Суда РФ. Резюмируя проанализированные данные, автор, в частности, особо подчеркнула, «что в практике работы зарубежных архивов и библиотек активно используется право ОТКАЗА пользователю в осуществлении самокопирования» ${ }^{2}$. В комментариях развернулась целая баталия с участием архивистов, историков, пользователей архивов, в которой уточнялись фактические данные по зарубежным архивам и обсуждались реалии российской архивной действительности ${ }^{3}$. Отметим, что к этому времени пользователи зарубежных архивов активно делились информацией о практике самостоятельного копирования в зарубежных архивах, и эти данные были собраны воедино и размещены в сообществе «Исторический архив» в социальной сети Facebook ${ }^{4}$.

Но одними обсуждениями в социальных сетях проблемы самостоятельного копирования дело, конечно же, не ограничилось. Поскольку после исторического решения Верховного Суда РФ Росархив разослал циркулярное письмо по федеральным архивам и государственным учреждениям, регулирующим отношения в сфере архивного дела, с

1 Исследователь в архиве: новые правила. Интервью с А. В. Галиничевым и Д. С. Пославским // Историческая экспертиза. 2016. № 3. С. 295-315. URL:

https://istorex.ru/page/issledovatel_v_arkhive_novie_pravila_intervyu_s_av_galinichevim_i_ds_poslavskim (дата обращения: 10.11.2018).

2 Юмашева Ю. Ю. Международный опыт решения проблемы самостоятельного цифрового копирования в читальных залах архивов и библиотек // Историческая информатика. 2017. № 2. URL: http://printed.enotabene.ru/istinf/article_21905.html?fbclid=IwAR241QHMwtRbtLgLX2xYuhN0Oq4_IKeBxikWsLRDW7c8dNAujD 4sHUTkrqM (дата обрашения: 10.11.2018).

${ }^{3}$ Кирилл Белоусов. Самостоятельное копирование документов в зарубежных архивах: [Обсуждение статьи Ю. Ю. Юмашевой]. 14 ноября 2017 г.

URL: https://www.facebook.com/photo.php?fbid=1520792791342326\&set=a.475368785884737\&type=3 (дата обращения: 10.11.2018).

4 Исторический архив. Самостоятельное фотокопирование в зарубежных архивах. 3 августа 2016 г. (с дополнениями от 6 августа и 10 ноября 2016 г.)

URL: https://www.facebook.com/histarchive/photos/a.263630910475724/548797158625763/?type=3\&permPage=1 (дата обращения: 10.11.2018). 
«рекомендацией» предоставлять услугу самостоятельного копирования архивных документов только на платной основе, а федеральные архивы и большинство региональных архивов восприняли эту рекомендацию (по понятным причинам) как руководство к действию, пользователи начали оспаривать законность такой услуги в органах прокуратуры и других надзорных инстанциях. В абсолютном большинстве случаев решения принимались в пользу заявителей. Однако летом 2017 г. Росархиву удалось изменить Федеральный закон «Об архивном деле в Российской Федерации» и на основе этих изменений ввести в ноябре 2017 г. новый «Порядок использования архивных документов в государственных и муниципальных архивах», который обязывал архивы предоставлять услугу по самостоятельному копированию документов только на возмездной основе 5 .

Далее, несколько слов хотелось бы сказать о формах общения архивов и пользователей сегодня. Собственно, основное персональное общение происходит в читальных залах архивов между сотрудниками и пользователями. Чаще всего оно благожелательное, но, конечно, и пользователи встречаются с неважными характерами, и сотрудники не всегда могут сдержать свое раздражение по тому или иному поводу. Однако данная форма не позволяет решать каких-то общеинституциональных проблем.

Следующая форма общения - обращения граждан с пожеланиями или жалобами в Федеральное архивное агентство либо в государственное учреждение, регулирующее отношения в сфере архивного дела. Но здесь также наличествует ряд ограничений. Прежде всего, низкая активность пользователей архивов. Количество обращений в Росархив за год не превышает несколько десятков случаев. Представляется, что на местах картина примерно та же самая. Недовольства чем-либо (плохое освещение рабочих мест, устаревшая техника для просмотра микрофильмов, неудобный режим работы читального зала, запрет на использование электрических розеток, несоответствие сроков и объемов выдачи дел «Порядку использования» и многое другое) или предложений со стороны посетителей читальных залов высказывается много, но в кругу своих, кулуарно. Транслировать их полномочным архивным органам управления пользователи чаще всего боятся. Когда на прошедшей в сентябре 2018 г. конференции «Архивные документы в сети Интернет: Pro et Contra», организованной Архивным комитетом Санкт-Петербурга, мной был упомянут такой фактор взаимоотношений архивистов и пользователей как страх, тут же из президиума раздался вопрос: «С чьей стороны?». Очевидный для меня ответ оказался не таким уж очевидным. Архивисты тоже боятся пользователей. И такая ситуация ненормальна. Чтобы преодолеть этот страх друг друга, необходимо больше взаимодействовать.

А активно взаимодействуют с архивной администрацией в нашей стране не более двух десятков активистов (наиболее активно - лишь 5-7), которые постоянно пишут в инстанции и пытаются улучшить условия работы для пользователей. В итоге, у архивного руководства складывается впечатление, что абсолютное большинство пользователей все устраивает, но есть горстка недовольных, которыми движет личный корыстный интерес, а значит ими можно пренебречь. Это позволяет ему в официальных ответах на запросы обходиться общими формулировками и красивыми фразами, которые никакого ответа на поставленный вопрос не дают.

Формально, для взаимодействия с обществом, при органах управления архивным делом функционируют Общественные советы. Но работают они именно формально. Состав советов и порядок их комплектования заставляет усомниться в общественной природе этого института. На их рассмотрение не выносятся острые и болезненные вопросы архивной отрасли, затрагивающие интересы пользователей. При Федеральном архивном агентстве Общественный совет собирается достаточно регулярно, но лишь для того, чтобы выполнить

\footnotetext{
5 Подробно историю противостояния пользователей и архивов на ниве самостоятельного копирования изложил Кирилл Белоусов в своей недавней статье: Белоусов $K$. $A$. О самостоятельном копировании архивных документов в читальных залах архивов России // Генеалогический вестник. 2018. № 58. C. 72-78. URL: https://www.facebook.com/arhdoc/posts/1936256866462581 (дата обращения: 10.11.2018).
} 
свою функцию: одобрить решения, организуемые мероприятия, отчеты и т.п. Росархива, как подлежащие обсуждению Общественным советом по закону. В регионах такие советы и вовсе могут существовать только на бумаге либо собираться раз в год.

Еще одна форма взаимодействия, применяемая в зарубежных архивах, - волонтерские организации, создаваемые при архивных учреждениях. Но в нашей архивной действительности это пока какое-то необозримое будущее, за единичными исключениями.

На наш взгляд, наиболее демократичной по форме и эффективной по сути могла бы стать площадка, предоставляемая социальными сетями. Она уже активно используется первыми лицами государств как инструмент доведения информации до самих широких слоев населения и получения обратной связи. Надо отметить, что за последние два года это направление коммуникации активно развивается и в архивной среде: архивы или органы управления архивным делом заводят свои официальные или неофициальные страницы в социальных сетях и видеохостингах (Вконтакте, Facebook, Instagram, YouTube). Первопроходцем или одним из самых первых стал Российский государственный архив литературы и искусства, открывший свой аккаунт в Facebook ${ }^{6}$ в 2012 г. На сегодняшний день на страницу архива подписано 4370 человек. В апреле 2018 г. в соцсети Вконтакте заработала официальная страница Федерального архивного агентства ${ }^{7}$ количество подписчиков на 13 ноября 2018 г. - 714 человек.

Однако пока страницы архивов не становятся площадками для обсуждения проблем, а являются популяризаторами документов, которые хранит архив, или ретрансляторами новостных сообщений с официальных сайтов архивов, живого диалога по-прежнему не выходит. Конечно, главная проблема этого формата - ответственность администратора страницы, его полномочия, в рамках которых он может отвечать на те или иные вопросы, представлять официальную позицию руководства архивного учреждения. На уже упоминавшейся конференции «Архивные документы в сети Интернет: Pro et Contra» озвученная проблема поднималась представителем Службы по делам архивов ХантыМансийского автономного округа. Ольга Александровна Спиридонова, приведя пример сложной ситуации, возникшей в комментариях под новостью на странице архива в соцсети, предположила, что «руководитель организации, архива всегда должен держать руку на пульсе и быть активным участником страницы» ${ }^{8}$. На наш взгляд, позиция верная. Но представляется, что в архивном учреждении должен быть определен некий вектор развития, в рамках которого администратор страницы мог бы отвечать на не самые сложные вопросы, выражая позицию архива.

Другая сложность данного формата - разводить дискуссионные вопросы и запросы частного характера, которые исполняются архивом на платной основе. Администратор страницы вполне может свободно консультировать подписчиков по структуре научносправочного аппарата, составу и содержанию фондов, отдельных видов документов, вести просветительскую деятельность по ликвидации архивной безграмотности граждан. Но это уже работа, а не хобби или дополнительно взятые на себя в инициативном порядке обязательства. Руководство архива должно это понимать.

Для иллюстрации же нынешнего положения приведем такой пример. 18 июня 2018 г. одним из подписчиков страницы Росархива Вконтакте был задан такой вопрос: «Будет ли

\footnotetext{
${ }^{6}$ РГАЛИ на Facebook. URL: https:/www.facebook.com/Russian-State-Archive-of-Literature-and-Art165003436929198 (дата обращения: 10.11.2018).

7 Официальная страница Федерального архивного агентства в социальной сети Вконтакте. URL: https://vk.com/rusarchives

8 Архивные документы в сети Интернет: Pro et Contra. День 2: Меншиковский дворец. Выступление консультанта службы по делам архивов Ханты-Мансийского автономного округа О. А. Спиридоновой «Интернет-ресурсы Архивной службы Югры и перспективы их развития». Тайминг: начало выступления с 43:55, цитата с 1:00:22. URL: https:/www.youtube.com/watch?v=m4sFhvrqYZQ\&t=4325s (дата обращения: 10.11.2018).
} 
выложен в открытый доступ двухтомный сборник “Архивы и власть"9?». Последовал быстрый ответ администратора страницы: «На данный момент не располагаем достоверной информацией, НО обязательно проинформируем по данному вопросу» ${ }^{10}$. К сожалению, по состоянию на 13 ноября 2018 г., ответ так и не получен.

Подводя итог этому небольшому сообщению-размышлению, хочется отметить, что большинство обозначенных проблем проистекает от колоссальной недофинансированности архивной отрасли. Но здесь уже архивисты не готовы отстаивать свою значимость в глазах государства, хотя она очевидна. Казалось бы, переподчинение Росархива от Министерства культуры РФ к президенту страны должно было открыть широкие возможности для развития архивной отрасли. Увы, но пока Росархив предпочитает бороться с пользователями, нежели реализовывать возможности уже наступившей новой эпохи информации, к которой архивы катастрофически не готовы, ни в нормативно-правовом отношении, ни в техническом, ни в кадровом.

Возможно, скажу крамольную вещь, но информационная эра выдвигает на первый план ценность информации (со всеми оговорками, связанными $\mathrm{c}$ eе верификацией, достоверностью и подлинностью), а не ее носителя, т. к. этот носитель все больше теряет свои физические характеристики - он дематериализуется в традиционном смысле. Поэтому очень важно ввести в информационное поле те три-четыре столетия задокументированной российской истории, когда информация интенсивно создавалась и передавалась на бумажном носителе.

Для архивиста сегодня в первую очередь ценен носитель информации - бумажный документ. Оно и понятно, т.к. утратив носитель, мы теряем его содержимое. Однако современная архивная стратегия сохранности документа должна заключаться не только в обеспечении его бесконечно долгого физического существования, но в извлечении из него уникальной информации, обеспечении ее общедоступности и многотиражности. Иначе может случиться непоправимое - катастрофа Национального музея Бразилии.

\section{Материал поступил в редакияию 11.11.2018 2.}

\section{Лumepamypa}

Архивы и власть: Первое послереволюционное десятилетие. Протоколы и журналы заседаний руководящих органов управления архивной отраслью за 1918-1928 гг.: Сб. док.: В 2 т. / Отв. ред. О. Н. Копылова. М., 2018. Т. 1: 1918-1920 гг. 1040 с.; Т. 2: 1921-1928 гг. 920 с.

Белоусов K. A. О самостоятельном копировании архивных документов в читальных залах архивов России // Генеалогический вестник. 2018. № 58. С. 72-78. URL: https://www.facebook.com/arhdoc/posts/1936256866462581 (дата обращения: 10.11.2018).

Исследователь в архиве: новые правила. Интервью с А. В. Галиничевым и Д. С. Пославским // Историческая экспертиза. 2016. № 3. С. 295-315. URL:

https://istorex.ru/page/issledovatel_v_arkhive_novie_pravila_intervyu s_av_galinichevim_i ds_po slavskim (дата обращения: 10.11.2018).

Юмашева Ю. Ю. Международный опыт решения проблемы самостоятельного цифрового копирования в читальных залах архивов и библиотек // Историческая информатика. 2017. № 2. URL: http://printed.enotabene.ru/istinf/article 21905.html? fbclid=IwAR241QHMwtRbtLgLX2xYuhN0Oq4 IKeBxikWs LRDW7c8dNAujD4sHUTkrqM (дата обращения: 10.11.2018).

\footnotetext{
${ }^{9}$ Речь идет о следующем издании: Архивы и власть: Первое послереволюционное десятилетие. Протоколы и журналы заседаний руководящих органов управления архивной отраслью за 1918-1928 гг.: Сб. док.: В 2 т. / Отв. ред. О. Н. Копылова. М., 2018. Т. 1: 1918-1920 гг. 1040 с.; Т. 2: 1921-1928 гг. 920 с.

10 URL-адрес поста, под которым появился комментарий: https://vk.com/wall-164851212_17. URL-aдpec комментария с вопросом: https://vk.com/wall-164851212_17?reply=21 (дата обращения: 10.11.2018).
} 


\section{References}

Arhivy i vlast': Pervoe poslerevolyutsionnoe desyatiletie. Protokoly i zhurnaly zasedaniy rukovodyashchih organov upravleniya arhivnoy otrasl'yu za 1918-1928 gg.: Sb. dok. [Archives and power: first decade after the revolution. Protocols and minute-books of the archival branch ruling bodies for 1918-1928. Collected documents.] / Otv. red. O. N. Kopylova. M., 2018. Vol. 1: 19181920. 1040 s.; Vol. 2: 1921-1928. 920 s.

Belousov K. A. O samostoyatel'nom kopirovanii arkhivnykh dokumentov v chital'nykh zalakh arkhivov Rossii [About free copying of archival documents at reading rooms of the Russian archives]. In:/ Genealogicheskij vestnik = Genealogical herald. 2018. № 58. P. 72-78. [Available at:] https://www.facebook.com/arhdoc/posts/1936256866462581.

Issledovatel' v arkhive: novye pravila. Interv'yu s A. V. Galinichevym i D. S. Poslavskim [A researcher in an archive: new rules. An interview with A. V. Galinichev and D. S. Poslavskiy]. In: Istoricheskaya ehkspertiza $=$ Historical expertize. 2016. № 3. P. 295-315. [Available at:] https://istorex.ru/page/issledovatel_v_arkhive_novie_pravila_intervyu_s_av_galinichevim_i_ds_po slavskim

Yumasheva Yu. Yu. Mezhdunarodnyy opyt resheniya problemy samostoyatel'nogo tsifrovogo kopirovaniya $\mathrm{v}$ chital'nykh zalakh arkhivov i bibliotek [International experience of solving the problem of free digital documents-copying in the reading rooms of archives and libraries]. In: Istoricheskaya informatika $=$ Historical informatics. 2017. № 2. [Available at:] http://printed.enotabene.ru/istinf/article_21905.html? fbclid=IwAR241QHMwtRbtLgLX2xYuhN0Oq4_IKeBxikWs LRDW7c8dNAujD4sHUTkrqM (data obrashcheniya: 10.11.2018). 